OPEN ACCESS

Edited by:

Antonio Francesco Corno,

Glenfield Hospital, UK

Reviewed by:

Patrick O. Myers,

Geneva University Hospitals,

Switzerland

Meena Nathan,

Boston Children's Hospital, USA

*Correspondence:

Lindsay M. Ryerson

ryerson@ualberta.ca

Specialty section: This article was submitted to

Pediatric Cardiology,

a section of the journal

Frontiers in Pediatrics

Received: 06 April 2016

Accepted: 10 June 2016

Published: 22 June 2016

Citation:

Ryerson LM and Lequier LL (2016) Anticoagulation Management and Monitoring during Pediatric Extracorporeal Life Support: A Review of Current Issues.

Front. Pediatr. 4:67.

doi: 10.3389/fped.2016.00067

\section{Anticoagulation Management and Monitoring during Pediatric Extracorporeal Life Support: A Review of Current Issues}

\author{
Lindsay M. Ryerson* and Laurence L. Lequier \\ Pediatric Critical Care, Stollery Children's Hospital, Edmonton, AB, Canada
}

Anticoagulation is an imperfect science and is even more complicated in neonates and young children. The addition of the extracorporeal life support (ECLS) foreign circuit adds an additional layer of complexity. Anticoagulation goals during ECLS are to maintain a clot-free circuit and a hemostatically balanced patient. Unfractionated heparin (UFH) is the default gold standard anticoagulant as no large studies have been performed on any other anticoagulants. This review will focus on the advantages and disadvantages of the various methods to monitor UFH anticoagulation, discuss alternative anticoagulants, and examine bleeding and thrombotic complications during ECLS.

Keywords: pediatrics, anticoagulation, extracorporeal life support, heparin, bleeding

\section{ANTICOAGULATION IS AN IMPERFECT SCIENCE AND IS MORE COMPLEX IN NEONATES AND YOUNG CHILDREN}

Unfractionated heparin (UFH) remains the anticoagulant of choice in pediatrics due to its short halflife and potential for reversal by protamine sulfate. Recommendations for laboratory monitoring of UFH in children have been extrapolated from adult recommendations $(1,2)$. The activated partial thromboplastin time (aPTT) and anti-Xa assays, both routine anticoagulation monitoring tests, were developed based on the adult hemostatic system. Infants and children have differences in hemostasis compared with adults. Procoagulant proteins (Factors II, VII, IX, X, XI, and XII) and inhibitors of coagulation [Protein C, Protein S, antithrombin (AT), and $\alpha 2$ macroglobulin] are present in different quantities, and the fibrinolytic system is relatively downregulated in young children. These normal physiologic differences are termed "developmental hemostasis" (3-5).

A prospective study examining the use of UFH and monitoring by standard tests (aPTT and anti$\mathrm{Xa}$ ) in neonatal and pediatric patients [not on extracorporeal life support (ECLS)] demonstrated poor correlation between UFH dose and both aPTT and anti-Xa (6). There was no correlation between aPTT and anti-Xa (6).

\section{ANTICOAGULATION ON ECLS ADDS AN ADDITIONAL LAYER OF COMPLEXITY}

The ECLS circuit contains a large foreign surface area that causes a massive inflammatory response, which affects both the cellular and plasma components of blood. Shear stresses imposed by the ECLS circuit activate cellular blood elements, including platelets and leukocytes, as well as plasma elements, such as von Willebrand factor. The initiation of ECLS is associated with a significant increase 
in activation markers of the coagulation system suggesting a consumptive coagulopathy (7). This may further exacerbate the loss of both pro- and anticoagulant proteins.

It is impossible to completely control the interaction between blood and the biomaterials of the ECLS circuit; this results in a shift to a hypercoagulable state. Consequently, antithrombotic therapy is necessary to prevent both circuit and patient thrombosis. Clinicians must balance the risk of bleeding complications with the need to maintain appropriate circuit flows and avoid thrombosis. A continuous UFH infusion is the default gold standard anticoagulant in ECLS; there are no large ECLS studies on any anticoagulants other than UFH. The optimal method to measure UFH efficacy on ECLS is unknown.

\section{HEPARIN IS AN INDIRECT ANTICOAGULANT}

Heparin is a heterogeneous mixture of branched glycoaminoglycans in saccharide chains. UFH is a mixture of different molecular weights (ranging from 3000 to $30,000 \mathrm{kDa}$ ) and corresponding saccharide chain lengths (1). Heparin is an indirect anticoagulant in that it requires AT for its primary anticoagulant action, inhibition of both thrombin and FXa. UFH does not inhibit clot-bound thrombin or thrombin bound to the ECLS circuit. The anticoagulant activity of UFH is variable for two reasons: (1) only one-third of an administered dose of UFH has the specific, active pentasaccharide sequence that binds AT and (2) the anticoagulant profile of UFH is influenced by the chain length of the molecules (1).

Unfractionated heparin binds to AT via a unique glucosamine unit that contains a specific, active pentasaccharide sequence (1). The UFH/AT complex is responsible for the anticoagulant action of UFH by inhibition of Factors IIa (thrombin), Factors Xa, IXa, $\mathrm{Xia}$, and XIIa. Once bound, the UFH/AT complex has $1000 \times$ the inhibitory effect compared with AT alone. The remaining two-third of the UFH dose, without the active pentasaccharide sequence, has minimal anticoagulant action at therapeutic doses and may, in fact, inhibit anticoagulation by binding to plasma proteins and activating platelets (1).

Heparin molecules are made up of different lengths of saccharide chains. UFH inhibits thrombin by AT binding via the high affinity pentasaccharide sequence as well as binding directly to the coagulation enzyme (1). Inhibition of FXa requires only the binding of AT to UFH via the specific pentasaccharide sequence. Thrombin (IIA) and Factor Xa are the most sensitive to inhibition by UFH/AT complex (1). However, only heparin molecules of 18 or greater saccharide units are able to catalyze the interaction of both AT and thrombin. If the heparin saccharide chain is too short, it is unable to catalyze thrombin inhibition (1). As a result, there may be inhibition of FXa, but not of thrombin, which leads to variable anticoagulation. This heterogeneity makes monitoring of anticoagulation difficult.

\section{STANDARD MONITORING OF COAGULATION IS IMPERFECT}

Monitoring of coagulation is done in vitro, which eliminates the effects of the endothelium in vivo. This flaw is a major limitation in our understanding of how coagulation occurs in the patient. A second limitation is that the majority of our coagulation tests are plasma-based tests, partial functional measures of coagulation, and not whole blood tests that incorporate platelet function and assessment of clot strength. Table 1 summarizes the advantages and disadvantages of different UFH monitoring techniques.

\section{Activated Clotting Time}

The activated clotting time (ACT) is the only routine whole blood test performed on ECLS. ACT measures the time in seconds of whole blood to form fibrin clot after the addition of various coagulation activators. ACT does not measure clot strength. ACT was invented in the 1960s for cardiopulmonary bypass $(\mathrm{CPB})$ and since then has been applied to various settings requiring UFH anticoagulation. ACT results will vary based on many factors including platelet number and function, fibrinogen level, coagulation factor deficiencies, patient temperature, hemodilution, and technical factors (8). Hence, it does not represent, solely, UFH effect. Furthermore, different ACT machines yield different results either because of different coagulation activators or because they are measuring different end points. For example, a common point-of-care (POC) ACT in the United States is the Hemochron System, either the Hemochron Response or the Hemochron Signature Elite. Both of these systems look at the time of whole blood to form clot, but measure this end point differently. The Hemochron Response System uses magnet technology; clot endpoint occurs with a specific displacement of the magnet. The Hemochron Signature Elite System detects clot formation by LED optical detectors that measure the speed of the blood sample. The instrument recognizes that a clot endpoint has been achieved when the movement decreases below a predetermined rate. Unfortunately, these systems cannot be used interchangeably (9).

\begin{tabular}{|c|c|c|}
\hline Test & Advantages & Disadvantages \\
\hline ACT & $\begin{array}{l}\text { - Inexpensive } \\
\text { - POC } \\
\text { - Whole blood test }\end{array}$ & $\begin{array}{l}\text { - Measures end point of the } \\
\text { clotting cascade, but does not } \\
\text { solely tell you about UFH effect }\end{array}$ \\
\hline aPTा & $\begin{array}{l}\text { - Accepted means of titrating } \\
\text { anticoagulation therapy for both } \\
\text { UFH and DTI } \\
\text { - POC now available }\end{array}$ & $\begin{array}{l}\text { - High degree of intra- and } \\
\text { interpatient variability } \\
\text { especially in infants } \\
\text { - Less reliable in critical illness }\end{array}$ \\
\hline Anti-Xa & $\begin{array}{l}\text { - Specific measure of UFH effect } \\
\text { based on the ability of UFH } \\
\text { to catalyze AT's inhibition of } \\
\text { factor Xa } \\
\text { - Better association with UFH } \\
\text { dose }\end{array}$ & $\begin{array}{l}\text { - Elevated plasma- } \\
\text { free hemoglobin and } \\
\text { hyperbilirubinemia will } \\
\text { underestimate UFH activity by } \\
\text { anti-Xa }\end{array}$ \\
\hline $\begin{array}{l}\text { TEG/ } \\
\text { ROTEM }\end{array}$ & $\begin{array}{l}\text { - POC } \\
\text { - Whole blood test } \\
\text { - Provides information about both } \\
\text { clot strength and fibrinolysis }\end{array}$ & - Limited availability \\
\hline
\end{tabular}

UFH, unfractionated heparin; POC, point-of-care; AT, antithrombin; DTI, direct thrombin inhibitor; TEG, thromboelastography; ROTEM, rotational thromboelastometry. 
The I-STAT ACT is another POC ACT system. It is similar to traditional ACT tests except that the endpoint is indicated by the conversion of a thrombin product other than fibrinogen, and an electrochemical sensor is used to indicate this conversion. There is variability between different ACT monitoring systems, which makes comparisons between centers using different systems impossible (10).

Baird and colleagues retrospectively reviewed over 600 pediatric ECMO patients and found only a modest correlation ( $r=0.48$ ) between ACT and UFH dose suggesting that ACT is not an accurate tool for monitoring UFH anticoagulation during pediatric ECMO (8). Other reports examining the correlation of UFH and ACT on ECLS provided mixed results varying from either no statistical correlation $(11,12)$ to a better correlation within individual patients (13).

\section{Activated Partial Thromboplastin Time}

Historically, dose monitoring of patients receiving UFH has been with the aPTT. The aPTT is a plasma-based test that measures the time from Factor XII activation to fibrin formation, after addition of calcium and a reagent. A prospective, adult study suggested that an aPTT between 1.5 and $2.5 \times$ normal was associated with a decreased risk of recurrent venous thromboembolism (2). Based on this adult study, the therapeutic range for the aPTT was set at $1.5-2.5 \times$ the patient's pre-therapy baseline aPTT; however, this was validated neither in randomized controlled trials nor in children.

The use of aPTT for monitoring UFH is based on the assumption that the patients' baseline aPTT is comparable to normal controls; this assumption is critical for the linear relationship between UFH dose and aPTT. Unfortunately, the baseline aPTT in sick pediatric patients is very different from normal controls, which limits the utility of aPTT as a measure of UFH effect. Increased levels of non-specific acute phase reactants, Factor VIII, and fibrinogen often escalate in critically ill infants and children; increased levels of these proteins may falsely shorten the aPTT masking true UFH effect (6). As a result, aPTT demonstrates a high degree of intra- and interpatient variability, which resulted in increased number of blood tests for monitoring and frequent dose changes. Consequently, many clinical laboratories and clinicians have substituted the anti-Xa assay for UFH monitoring.

\section{Anti-Xa Assay}

The anti-Xa assay (alternatively called the heparin level) is a measure of UFH effect based on the ability of UFH to catalyze AT's inhibition of Factor Xa. Anti-Xa is a plasma-based test that does not incorporate platelet function. The anti-Xa assay evaluates only one chemical reaction of the UFH-AT complex; it does not measure inhibition of thrombin. The anti-Xa is used as a surrogate measure of the overall anticoagulant activity of UFH. The same adult study that set the therapeutic aPTT at $1.5-2.5 \times$ the patient's baseline aPTT demonstrated that this therapeutic aPTT range corresponded to an anti-Xa activity of $0.3-0.7 \mathrm{U} / \mathrm{mL}(2)$.

A number of single-center ECLS case series have found an improved association of anti-Xa with UFH dose as well as an associated decrease in blood sampling, decrease in blood product transfusion, and less complications, both thrombotic and hemorrhagic, while using anti-Xa as a part of UFH monitoring protocol during ECLS (13-17). The anti-Xa assay is a chromogenic assay, which can limit its utility in ECLS as the anti-Xa is falsely decreased when there is elevated plasma-free hemoglobin or bilirubin (18).

Newall and colleagues prospectively compared UFH concentration via protamine titration and UFH effect via aPTT, anti-Xa, and thrombin clotting time (TCT) in a group of pediatric patients in the cardiac catheterization laboratory (19). Protamine titration is considered the gold standard of UFH concentration in plasma. Their results refute the pediatric recommendations for UFH management extrapolated from adult trials. Agreement between all measures of UFH effect and protamine titration was poor (19). They propose that the current recommendations for management of UFH in pediatrics are inappropriate, which demands either different tests for monitoring UFH efficacy or alternative anticoagulants.

\section{Viscoelastic Testing}

Viscoelastic tests [thromboelastography (TEG) and rotational thromboelastometry (ROTEM)] examine whole blood clot formation (coagulation) and dissolution (fibrinolysis). They are limited by static conditions (no flow) as well as the exclusion of vascular endothelium, but they are the only option available to evaluate clot strength. Additional benefits include POC testing that can be performed at the bedside and at the patient's temperature. Additional information from viscoelastic testing includes time until initial fibrin formation, the kinetics of fibrin formation and clot development, the ultimate strength and stability of the fibrin clot, clot lysis, and platelet function (20). TEG and ROTEM are not yet widely available; only $43 \%$ of centers use viscoelastic tests as part of their routine anticoagulation monitoring on ECLS (21). There are limited reports documenting improved outcomes when TEG was incorporated into a bundled anticoagulation protocol (22).

\section{ANTITHROMBIN REPLACEMENT}

The optimal AT level for any patient receiving UFH anticoagulation is unknown. In infants and children with escalating UFH requirements and/or clinically inadequate anticoagulant effect, relative AT deficiency may be a contributing factor. There is insufficient experience to provide evidence-based recommendations for AT concentrate use in children on ECLS.

If low AT levels are confirmed, AT replacement may be considered (23-26). AT concentrate and recombinant AT are now available and some centers will prophylactically replace it for AT activity $<50-80 \%(<0.5-0.8 \mathrm{U} / \mathrm{mL})$. Some centers will treat low AT levels only if there is evidence of reduced UFH effect based on low anti-Xa levels or minimal UFH effect on TEG kaolin versus TEG heparinase samples.

Of the ECLS programs that use AT replacement routinely as part of their anticoagulation protocol, most target levels from $>50$ to $>100 \%$. The use of AT concentrate is preferred over the administration of frozen plasma (FP) as giving standard bolus infusions of FP does not easily achieve adequate AT levels (may 
need $>20 \mathrm{~mL} / \mathrm{kg}$ for FP to obtain clinical AT effect as standard plasma contains only $1 \mathrm{U} / \mathrm{mL}$ for AT).

The UFH infusion can be decreased (up to 50\%) prior to AT replacement because of the potential for significant augmentation of UFH's anticoagulant effect. ACT and anti-Xa should be checked 30-60 min after AT administration to evaluate UFH effect.

\section{ALTERNATIVE ANTICOAGULANTS}

It is impossible to provide high quality evidence supporting the use of UFH alternatives on ECLS. However, there is increasing experience with alternative anticoagulants.

\section{Direct Thrombin Inhibitors}

Direct thrombin inhibitors (DTIs) are not dependent on AT for their anticoagulant effect. They act directly to inhibit both circulating and clot-bound thrombin. DTIs are superior to UFH in their ability to inhibit clot-bound thrombin (27). Bivalirudin is a potentially attractive DTI as it is cleared mainly by intravascular proteolytic degradation and less so by the kidneys (27). Bivalirudin may be used as the initial anticoagulant on ECLS or patients may be transitioned to bivalirudin in cases of heparin-induced thrombocytopenia (HIT) or heparin resistance. Argatroban and lepirudin are other possible DTIs, but they rely on hepatic and renal clearance, respectively, which are organ systems often compromised on ECLS. Bivalirudin has a short half-life of 25-35 min, which is even shorter in children (27). Bleeding from bivalirudin is potentially reversible with activated Factor VII. Bivalirudin is approved for use as an anticoagulant in adult patients undergoing angioplasty. There is off-label experience using bivalirudin infusions in adult patients with HIT demonstrating successful anticoagulation with a target aPTT of $1.5-2.5 \times$ normal (28).

There is minimal experience with bivalirudin in pediatric populations and even less in pediatric ECLS. Nagle and colleagues report a series of 12 children transitioned to bivalirudin because of UFH resistance, UFH failure, or HIT on ECLS (29). Their maintenance dose range of bivalirudin was very wide due to significant interpatient variability. They followed aPTT, but do not report their target range. Retrospective adult studies comparing UFH and bivalirudin on ECLS demonstrated no difference in thromboembolic complications $(30,31)$.

There are evolving challenges with use of bivalirudin on ECLS. Bivalirudin does not work well when there is blood stasis, which is common on ECLS requiring the change of different circuit components and is worrisome for the development of intraventicular clot if the heart is not ejecting (32). Bivalirudin also falsely elevates INR (30). ACT does not appear to be useful in monitoring of bivalirudin, and while aPTT may be limited by poor linearity and reproducibility, it is the most common monitoring test. Most centers will initially target a lower therapeutic range (aPTT of $1.5-2.0 \times$ normal) and increase the target aPTT to $1.5-2.5 \times$ normal as necessary for optimal circuit mechanics. Table 2 compares UFH and bivalirudin.

\section{New Oral Anticoagulants}

Rivaroxaban is a highly specific inhibitor of Factor Xa, which prevents the formation of the thrombin burst by inhibiting coagulation at the point of amplification (33). There is limited in vivo evidence in pediatrics. Oral factor-IIa inhibitors, such as dabigatran, are in use in adult patient for the prevention and treatment of thromboembolism. There is no data in adult ECLS. Their enteral administration and the paucity of pediatric studies will limit their use in pediatric ECLS.

\section{Factor XIla Inhibitors}

A new and alternative anticoagulation therapy based on an antibody to Factor XIIa was studied in an animal extracorporeal circuit model (34). This model demonstrated that a recombinant human FXIIa neutralizing antibody prevented fibrin deposition and thrombosis in the extracorporeal circuit and did not increase clinical bleeding.

\section{PREVENTION AND MANAGEMENT OF BLEEDING AND THROMBOTIC COMPLICATIONS}

\section{What Is Considered Significant Bleeding on ECLS?}

Both bleeding and thrombotic complications are associated with increased morbidity and mortality $(35,36)$. Complications reported in the ECLS literature are based on Extracorporeal Life Support Organization (ELSO) registry data that are nonspecific. A patient hemorrhagic complication is defined as one that requires transfusion or other intervention. We suggest that

TABLE 2 | Comparison of UFH and bivalirudin.

\begin{tabular}{|c|c|c|c|c|c|}
\hline Anticoagulant & $\begin{array}{l}\text { Mechanism of } \\
\text { action }\end{array}$ & Dosing range & Reversible & $\begin{array}{l}\text { Monitoring } \\
\text { tests }\end{array}$ & Limitations \\
\hline UFH & $\begin{array}{l}\text { Indirect - needs } \\
\text { AT for maximal } \\
\text { therapeutic effect }\end{array}$ & $10-70 \cup / k g / h$ & Protamine sulfate & $\begin{array}{l}\text { ACT, aPTT, } \\
\text { anti-Xa, and } \\
\text { TEG/ROTEM }\end{array}$ & $\begin{array}{l}\text { - Only one-third of UFH molecules has pentasaccharide } \\
\text { sequence that binds AT, which leads to variable } \\
\text { anticoagulation } \\
\text { - Does not inhibit clot-bound thrombin } \\
\text { - Thrombocytopenia }\end{array}$ \\
\hline Bivalirudin & $\begin{array}{l}\text { Direct thrombin } \\
\text { inhibitor }\end{array}$ & $\begin{array}{l}0.3-1.2 \mathrm{mg} / \\
\mathrm{kg} / \mathrm{h}\end{array}$ & $\begin{array}{l}\text { No specific antidote, but bleeding } \\
\text { may be mitigated with factor VIla }\end{array}$ & $\mathrm{aPTT}$ & $\begin{array}{l}\text { - Expect INR will increase } \\
\text { - Thrombosis with blood stasis (intracardiac and circuit) }\end{array}$ \\
\hline
\end{tabular}

UFH, unfractionated heparin; AT, antithrombin; TEG, thromboelastography; ROTEM, rotational thromboelastometry. 
clinically relevant bleeding be defined more specifically. Major bleeding may be defined as clinically overt bleeding associated with a hemoglobin drop of at least $20 \mathrm{~g} / \mathrm{L}$ in a 24-h period; bleeding that is retroperitoneal, pulmonary, or involves the central nervous system (CNS); bleeding $>20 \mathrm{~mL} / \mathrm{kg}$ over $24 \mathrm{~h}$; or bleeding that requires surgical intervention (37). Minor bleeding may be defined as bleeding of 10-20 mL/kg over $24 \mathrm{~h}$.

If there is excessive bleeding, particularly in postcardiotomy patients, holding the UFH for $4-6 \mathrm{~h}$ is reasonable. In some circumstances where bleeding is difficult to control, the UFH may be held up to $12 \mathrm{~h}$ or longer until bleeding is controlled.

\section{Antifibrinolytic Therapy}

There are no standardized dosing regimens for antifibrinolytic therapies on ECLS. These therapies are most commonly required to manage postoperative bleeding in the ECLS patient. Some centers use aminocaproic acid (Amicar) (38) or tranexamic acid (Cyklokapron) prophylactically in postcardiotomy patients, some use only prior to surgical intervention or when managing excessive bleeding, while others do not use at all. Amicar may be loaded (100 mg/kg IV bolus over $1 \mathrm{~h}$ ) and then followed by continuous infusion of $25-33 \mathrm{mg} / \mathrm{kg} / \mathrm{h}$ IV for at least $48 \mathrm{~h}$. Tranexamic acid typically run as an infusion from 10 to $16 \mathrm{mg} /$ $\mathrm{kg} / \mathrm{h}$ IV until bleeding subsides.

\section{Activated Factor VII}

There is conflicting data as to the safety and efficacy of activated Factor VII to manage refractory bleeding on ECLS (39-41). Activated Factor VIIa is considered for patients with severe, refractory hemorrhage only after the optimization of coagulation factors, fibrinogen, and platelets. Factor VIIa is usually given with platelets at a dose of $30-90 \mathrm{mcg} / \mathrm{kg}$ IV every $8 \mathrm{~h}$ for 3 doses.

\section{Thrombotic Complications in the Patient and the Circuit}

Circuit thrombosis becomes clinically relevant if it requires circuit intervention or is associated with severe hemolysis. Patient thromboses, particularly CNS infarcts, are likely underreported as not all patients receive neuroimaging after ECLS decannulation. Clinically relevant patient thrombosis, defined as an intracranial infarct demonstrated by neuroimaging after a change in a patient's neurologic exam or screening test, may be the most practical definition of a patient thrombotic complication. Other patient thrombotic complications, such as renal or splenic infarcts, require imaging for diagnosis.

\section{Heparin-Induced Thrombocytopenia}

Heparin-induced thrombocytopenia is an antibody-mediated event that results in paradoxical arterial and venous thrombosis. Since thrombocytopenia is common in critically ill patients and on ECLS, HIT is frequently suspected, but rarely diagnosed in pediatrics. The initial ELISA-based immunoassay that tests for the presence of antibodies against heparin-platelet factor 4 (PF4) conjugate is sensitive, but not specific (42). A serotonin release assay is typically performed as confirmatory testing when the immunoassay is positive (42).

\section{Optimal Blood Product Replacement}

There is a lack of studies that guide transfusion practices in ECLS patients. ELSO recommends that the patient is transfused to maintain a hemoglobin level of $140-150 \mathrm{~g} / \mathrm{L}$ (43). A recent survey by Bembea and colleagues found variable thresholds for blood product transfusion (21). The majority of pediatric centers used a hematocrit of $35 \%$ with a range of $25-40 \%$ as a trigger for transfusion of red blood cells (RBCs) (21). The median platelet count that triggered platelet transfusion was $100,000 \times 10^{9} / \mathrm{L}$ with a range of $50,000-200,000 \times 10^{9} / \mathrm{L}(21)$.

Given the association of positive fluid balance and mortality in pediatric critical care as well as the concern about storage issues with $\mathrm{RBC}$, some centers are re-examining their transfusion triggers. Fiser and colleagues recently examined the relationship between the transfusion of RBCs and changes in mixed venous saturation (SvO2) and cerebral regional tissue oxygenation, as measured by near infrared spectroscopy in patients supported with ECLS (44). The median hematocrit was 0.37 . The majority of transfusions resulted in no significant change in either SvO2 or cerebral NIRS. There was no relationship between pre-transfusion hematocrit and the change in either SvO2 or cerebral NIRS suggesting that RBC transfusion did not significantly alter global tissue oxygenation (44).

Agerstrand and colleagues performed a retrospective study of 38 adults receiving ECLS for ARDS after initiation of a blood conservation protocol that included a transfusion trigger of hemoglobin $<70 \mathrm{~g} / \mathrm{L}$, use of low dose anticoagulation targeting an aPTT of 40-60 s, and autotransfusion of circuit blood during decannulation (45). Only 24 patients (63\%) required transfusion over a median ECLS run of 9 days (45). Twenty-eight patients (73.7\%) survived to hospital discharge, which is comparable to the published literature. High survival rates with a hemoglobin transfusion trigger of $70 \mathrm{~g} / \mathrm{L}$ suggest that a conservative transfusion strategy may be applicable to this population (45).

\section{CONCLUSION}

Unfractionated heparin anticoagulation on ECLS is extremely variable due to the heterogeneity of UFH molecules and UFH's inability to inhibit clot-bound thrombin. As a result, it can be difficult to have a hemostatically balanced patient and a clean circuit. In addition, the ECLS patient population is critically ill, which may limit the use of standard anticoagulation monitoring tests. These tests are limited in that they are only partial functional measures of anticoagulation. Global measures of anticoagulation that use whole blood, incorporate platelets, and examine clot strength are becoming more widely available.

Bleeding and thrombotic complications are common in pediatric ECLS and are associated with increased mortality. Bivalirudin, a direct thrombin inhibitor, is a promising alternative anticoagulant as it avoids many of the limitations of UFH, but prospective rigorous studies are urgently needed. There remains a concern about increased risk of intracardiac thrombosis with bivalirudin if the heart is not ejecting. Additional studies are 
required to challenge the current dogma and evaluate triggers for blood product replacement.

Interested readers should refer to the ELSO Anticoagulation Guidelines and Patient-Specific Protocols available on the ELSO website (http://ELSO.org) for further reading.

\section{REFERENCES}

1. Hirsh J, Raschke R. Heparin and low molecular weigh heparin. The seventh ACCP conference of antithrombotic and thrombolytic therapy. Chest (2004) 126:188S-203S. doi:10.1378/chest.126.3_suppl.172S

2. Basu D, Gallus A, Hirsh J, Cade J. A prospective study of the value of monitoring heparin treatment with the activated partial thromboplastin time. N Engl J Med (1972) 287:327-327. doi:10.1056/NEJM197208172870703

3. Andrew M, Paes B, Milner R, Johnston M, Mitchell L, Tollefsen DM, et al. Development of the human coagulation system in the full-term infant. Blood (1987) 70:165-72.

4. Andrew M, Paes B, Milner R, Johnston M, Mitchell L, Tollefsen DM, et al. Development of the human coagulation system in the healthy premature infant. Blood (1988) 72:1651-7.

5. Andrew M, Vegh P, Johnston M, Bowker J, Ofosu F, Mitchell L. Maturation of the hemostatic system during childhood. Blood (1992) 80:1998-2005.

6. Kuhle S, Eulmesekian P, Kavanagh B, Massicotte P, Vegh P, Lau A, et al. Lack of correlation between heparin dose and standard clinical monitoring tests in treatment with unfractionated heparin in critically ill children. Haematologica (2007) 92:554-7. doi:10.3324/haematol.10696

7. Wong TE, Huang YS, Weiser J, Brogan TV, Shah SS, Witmer CM. Antithrombin concentrate use in children: a multicenter cohort study. J Pediatr (2013) 163:1329-34. doi:10.1016/j.jpeds.2013.06.036

8. Baird CW, Zurakowski D, Robinson B, Gandhi S, Burdis-Koch L, Tamblyn J, et al. Anticoagulation and pediatric extracorporeal membrane oxygenation: impact of activated clotting time and heparin dose on survival. Ann Thorac Surg (2007) 83:912-9. doi:10.1016/j.athoracsur.2006.09.054

9. Thenappan T, Swamy R, Shah A, Nathan S, Nichols J, Bond L, et al. Interchangeability of activated clotting time values across different point of care systems. Am J Cardiol (2012) 109:1379-82. doi:10.1016/j. amjcard.2011.12.033

10. Ojito JW, Hannan RL, Burogs MM, Lim H, Huynh H, Velis E, et al. Comparison of point of care activated clotting time systems utilized in a single pediatric institution. J Extra Corpor Technol (2012) 44:15-20.

11. Nankervis CA, Preston TJ, Dysart KC, Wilkinson WD, Chicoine LG, Welty SE, et al. Assessing heparin dosing in neonates on venoarterial extracorporeal membrane oxygenation. ASAIO J (2007) 53:111-4. doi:10.1097/01. mat.0000247777.65764.b3

12. Maul TM, Wolff EL, Kuch BA, Rosendorff A, Morell VO, Wearden PD. Activated partial thromboplastin time is a better trending tool in pediatric extracorporeal membrane oxygenation. Pediatr Crit Care Med (2012) 13:e363-71. doi:10.1097/PCC.0b013e31825b582e

13. Bembea MM, Schwartz JM, Shah N, Colantuoni E, Lehmann CU, Kickler T, et al. Anticoagulation monitoring during pediatric extracorporeal membrane oxygenation. ASAIO J (2013) 59:63-8. doi:10.1097/MAT.0b013e318279854a

14. Irby K, Swearingen C, Byrnes J, Byrant J, Prohan P, Fiser R. Unfractionated heparin activity measured by anti-factor Xa levels is associated with the need for extracorporeal membrane oxygenation circuit/membrane oxygenator change: a retrospective pediatric study. Pediatr Crit Care Med (2014) 15:e175-82. doi:10.1097/PCC.0000000000000101

15. Liveris A, Bello RA, Friedmann P, Duffy MA, Manwani D, Killinger JS, et al. Anti-factor Xa assay is a superior correlate of heparin dose than activated partial thromboplastin time or activated clotting time in pediatric extracorporeal membrane oxygenation. Pediatr Crit Care Med (2014) 15:e72-9. doi:10.1097/ PCC.0000000000000028

16. Northrop MS, Sidonio RF, Phillips SE, Smith AH, Daphne HC, Peitsch JB, et al. The use of an extracorporeal membrane oxygenation anticoagulation laboratory protocol is associated with decreased blood product use, decreased hemorrhagic complications, and increased circuit life. Pediatr Crit Care Med (2015) 16:66-74. doi:10.1097/PCC.0000000000000278

\section{AUTHOR CONTRIBUTIONS}

All authors listed, have made substantial, direct and intellectual contribution to the work, and approved it for publication.

17. O’Meara LC, Alten JA, Goldbert KG, Timpa JG, Phillips J, Laney D, et al. Anti-Xa directed protocol for anticoagulation management in children supported with extracorporeal membrane oxygenation. ASAIO J (2015) 61:339-44. doi:10.1097/MAT.0000000000000204

18. Kostousov V, Nguyen K, Hundalani SG, Teruya J. The influence of free hemoglobin and bilirubin on heparin monitoring by activated partial thromboplastin time and anti-Xa assay. Arch Pathol Lab Med (2014) 138:1503-6. doi:10.5858/arpa.2013-0572-OA

19. Newall F, Ignjatovic V, Johnston L, Summerhayes R, Lane G, Cranswick N, et al. Clinical use of unfractionated heparin therapy in children: time for a change? Br J Haematol (2010) 150:674-8. doi:10.1111/j.1365-2141.2010.08302.x

20. Ganter MT, Hofer CK. Coagulation monitoring: current techniques and clinical use of viscoelastic point-of-care coagulation devices. Anesth Analg (2008) 106:1366-75. doi:10.1213/ane.0b013e318168b367

21. Bembea MM, Annich GA, Rycus P, Oldenburg G, Berkowitz I, Provonos P. Variability in anticoagulation management of patients on extracorporeal membrane oxygenation: an international survey. Pediatr Crit Care Med (2013) 14:e77-84. doi:10.1097/PCC.0b013e31827127e4

22. Northrop MS, Sidonio RF, Phillips SE, Smith AH, Daphne HC, Pietsch JB, et al. The use of an extracorporeal membrane oxygenation anticoagulation laboratory protocol is associated with decreased blood product use, decreased hemorrhagic complications, and increased circuit life. Pediatr Crit Care Med (2015) 16:66-74. doi:10.1097/PCC.0000000000000278

23. Ryerson LM, Bruce AK, Lequier L, Kuhle S, Massicotte MP, Bauman ME. Administration of antithrombin concentrate in infants and children on extracorporeal life support improves anticoagulation efficacy. ASAIO J (2014) 60:559-63. doi:10.1097/MAT.0000000000000099

24. Agati S, Ciccarello G, Salvo D, Turla G, Ündar A, Mignosa C. Use of a novel anticoagulation strategy during ECMO in a pediatric population: singlecenter experience. ASAIO J (2006) 52:513-6.

25. Urlesberger B, Zobel G, Zenz W, Kuttnig-Haim M, Maurer U, Reiterer F, et al. Activation of the clotting system during extracorporeal membrane oxygenation in term newborn infants. J Pediatr (1996) 129:264-8. doi:10.1016/ S0022-3476(96)70252-4

26. Niebler RA, Christensen M, Berens R, Wellner H, Mikhailov T, Tweddell JS. Antithrombin replacement during extracorporeal membrane oxygenation. Artif Organs (2011) 35:1024-8. doi:10.1111/j.1525-1594.2011.01384.x

27. Warkentin TE. Bivalent direct thrombin inhibitors: hirudin and bivalirudin. Best Pract Res Clin Haematol (2004) 17:105-25. doi:10.1016/j.beha.2004.02.002

28. Francis J, Drexler A, Gwyn G, Moroose R. Bivalirudin, a direct thrombin inhibitor, in the treatment of heparin-induced thrombocytopenia. J Thromb Haemostas (2003) 1909. doi:10.1111/j.1538-7836.2003.tb00121.x

29. Nagle EL, Dager WE, Duby JJ, Roberts AJ, Kenny LE, Murthy MS, et al. Bivalirudin in pediatric patients maintained on extracorporeal life support. Pediatr Crit Care Med (2013) 14:e182-8. doi:10.1097/PCC.0b013e31827200b6

30. Pieri M, Agracheva N, Bonaveglio E, Greco T, De Bonis M, Covello RD, et al. Bivalirudin versus heparin as an anticoagulant during extracorporeal membrane oxygenation: a case-control study. J Cardiothor and Vasc Anesth (2013) 27:30-4. doi:10.1053/j.jvca.2012.07.019

31. Ranucci M, Ballotta A, Kandil H, Isgro G, Carlucci C, Baryshnikova E, et al. Bivalirudin-based versus conventional heparin anticoagulation for postcardiotomy extracorporeal membrane oxygenation. Crit Care (2011) 15:R275. doi:10.1186/cc10556

32. Warkentin TE, Greinacher A, Koster A. Bivalirudin. Thromb Haemost (2008) 99:830-9. doi:10.1160/TH07-10-0644

33. Attard C, Monagle P, Kubitza D, Ignjatovic V. The in-vitro anticoagulant effect of rivaroxaban in neonates. Blood Coagul Fibrinolysis (2014) 25:237-40. doi:10.1097/MBC.0000000000000033

34. Larsson M, Rayzman V, Nolte MW, Nickel KF, Björkqvist J, Jämsä A, et al. A factor XIIa inhibitory antibody provides thromboprotection in 
extracorporeal circulation without increasing bleeding risk. Sci Transl Med (2014) 6:222. doi:10.1126/scitranslmed.3006804

35. Dalton HJ, Garcia-Filion P, Holubkov R, Moler FW, Shanley T, Heidemann S, et al. Association of bleeding and thrombosis with outcome in extracorporeal life support. Pediatr Crit Care Med (2015) 16:167-74. doi:10.1097/ PCC. 0000000000000317

36. Werho DK, Pasquali SK, Yu S, Donohue J, Annich GM, Thiagarajan RR, et al. Hemorrhagic complications in pediatric cardiac patients on extracorporeal membrane oxygenation: an analysis of the extracorporeal life support organization registry. Pediatr Crit Care Med (2015) 16:276-88. doi:10.1097/ PCC. 0000000000000345

37. Mitchell LG, Goldenberg NA, Male C, Kenet G, Monagle P, Nowak-Gottl U. Definition of clinical efficacy and safety outcomes for clinical trials in deep venous thrombosis and pulmonary embolism in children. J Thromb Haemost (2011) 9:1856-8. doi:10.1111/j.1538-7836.2011.04433.x

38. Downard CD, Betit P, Chang RW, Garza JJ, Arnold JH, Wilson JM. Impact of AMICAR on hemorrhagic complications of ECMO: a ten-year review. J Pediatr Surg (2003) 38:1212-6. doi:10.1016/S0022-3468(03)00270-7

39. Long MT, Wagner D, Maslach-Hubbard A, Pasko DA, Baldridge P, Annich GM. Safety and efficacy of recombinant activated factor VII for refractory hemorrhage in pediatric patients on extracorporeal membrane oxygenation: a single center review. Perfusion (2014) 29:163-70. doi:10.1177/0267659113499782

40. Wittenstein B, Ng C, Ravn H, Goldman A. Recombinant factor VII for severe bleeding during extracorporeal membrane oxygenation following open heart surgery. Pediatr Crit Care Med (2005) 6:473-6. doi:10.1097/01. PCC.0000162449.55887.B9

41. Veldman A, Neuhaeuser C, Akintuerk H, Thul J, Gehron J, Schranz D, et al. rFVIIa in the treatment of persistent hemorrhage in pediatric patients on
ECMO following surgery for congenital heart disease. Pediatr Anesth (2007) 17:1176-81. doi:10.1111/j.1460-9592.2007.02328.x

42. Greinacher A. Heparin induced thrombocytopenia. N Engl J Med (2015) 373:252-61. doi:10.1056/NEJMcp1411910

43. Bartlett RH. Physiology of extracorporeal support. 4th ed. In: Annich GM, Lynch WR, MacLaren G, Wilson JM, Bartlett RH, editors. ECMO: Extracorporeal Cardiopulmonary Support in Critical Care. Ann Arbor: Extracorporeal Life Support Organization (2012). p. 11-31.

44. Fiser RT, Irbry K, Ward RM, Tang X, McKamie W, Prodhan P, et al. RBC transfusion in pediatric patients supported with extracorporeal membrane oxygenation: is there an impact on tissue oxygenation? Pediatr Crit Care Med (2014) 15:806-13. doi:10.1097/PCC.0000000000000222

45. Agerstrand CL, Burkart KM, Abrams DC, Bacchetta MD, Brodie D. Blood conservation in extracorporeal membrane oxygenation for acute respiratory distress syndrome. Ann Thorac Surg (2015) 99:590-6. doi:10.1016/j. athoracsur.2014.08.039

Conflict of Interest Statement: The authors declare that the research was conducted in the absence of any commercial or financial relationships that could be construed as a potential conflict of interest.

Copyright $\odot 2016$ Ryerson and Lequier. This is an open-access article distributed under the terms of the Creative Commons Attribution License (CC BY). The use, distribution or reproduction in other forums is permitted, provided the original author(s) or licensor are credited and that the original publication in this journal is cited, in accordance with accepted academic practice. No use, distribution or reproduction is permitted which does not comply with these terms. 